\title{
HUBUNGAN SIKAP DAN DUKUNGAN TENAGA KESEHATAN DENGAN KEBERHASILAN PEMBERIAN ASI EKSKLUSIF DI WILAYAH PUSKESMAS BERANGAS KAB. BARITO KUALA
}

\author{
Sixtia Kusumawati \\ Akademi Kebidanan Bunga Kalimantan \\ E-mail: :sixtia_wibowo@yahoo.co.id
}

\begin{abstract}
Breastfeeding is very important, especially in the early period of life. However, the practice of exclusive breastfeeding has not reached the expected target. The success of exclusive breastfeeding is influenced by several factors, one of which is the support factor from health workers including midwives. The purpose of this study was to determine the relationship between the attitude and support of health workers with the success of exclusive breastfeeding. This research was used research method for correlation study with cross sectional design. The population in this study were all mothers who had babies aged 6-12 months in the work area of the Berangas Health Center. The research sample was 78 people. The sampling technique was accidental sampling. The results showed 53 people (67.95\%) of whom had a positive attitude towards exclusive breastfeeding, 61 people (78.2\%) of whom received good support from health workers and 40 people (62.82\%) succeeded in exclusive breastfeeding. This study concludes that there is a significant relationship between the mother's attitude and the success of exclusive breastfeeding with a $p$ value of 0.004. This means that the more positive the attitude, the success rate in exclusive breastfeeding will also increase. There is a significant relationship between the support of health workers with the success of exclusive breastfeeding with a p value of 0.007. This means, the better the support provided by health workers, the success of exclusive breastfeeding will also increase.
\end{abstract}

Keywords: attitude, exclusive breastfeeding, health worker support.

\begin{abstract}
ABSTRAK
Pemberian ASI pada bayi sangat penting terutama dalam periode awal kehidupan. Akan tetapi, praktek dalam pemberian Air Susu Ibu (ASI) eksklusif belum mencapai target yang diharapkan. Keberhasilan ASI eksklusif dipengaruhi oleh beberapa faktor salah satunya adalah faktor dukungan dari tenaga kesehatan termasuk Bidan. Tujuan penelitian ini adalah untuk mengetahui hubungan sikap dan dukungan tenaga kesehatan dengan keberhasilan pemberian ASI eksklusif. Penelitian ini menggunakan metode penelitian untuk studi korelasi dengan desain cross sectional. Populasi dalam penelitian ini adalah seluruh ibu yang memiliki bayi umur 6-12 bulan di wilayah kerja Puskesmas Berangas. Sampel penelitian 78 orang. Teknik pengambilan sampel, yaitu accidental sampling. Hasil penelitian menunjukkan 53 orang $(67,95 \%)$ diantaranya memiliki sikap positif terhadap pemberian ASI eksklusif, 61 orang $(78,2 \%)$ diantaranya mendapat dukungan yang baik dari tenaga kesehatan dan 40 orang $(62,82 \%)$ berhasil memberikan ASI eksklusif. Penelitian ini menyimpulkan bahwa terdapat hubungan yang bermakna antara sikap Ibu dengan keberhasilan pemberian ASI eksklusif dengan nilai $\mathrm{p}$ sebesar 0,004 . Hal ini berarti bahwa semakin positif sikap, maka tingkat keberhasilan dalam pemberian ASI eksklusif juga akan meningkat. Terdapat hubungan yang bermakna antara dukungan tenaga kesehatan dengan keberhasilan pemberian ASI eksklusif dengan nilai p sebesar 0,007. Hal ini berarti, semakin baik dukungan yang diberikan oleh tenaga kesehatan, maka keberhasilan pemberian ASI eksklusif juga kan meningkat.
\end{abstract}

Keywords: ASI eksklusif, Dukungan Tenaga Kesehatan, Sikap 


\section{PENDAHULUAN}

Air susu ibu (ASI) merupakan sumber nutrisi terbaik yang dapat meningkatkan kesehatan ibu dan anak. Pemberian ASI pada bayi sangat penting terutama dalam periode awal kehidupan, oleh karena itu bayi cukup diberi ASI secara eksklusif selama 6 bulan pertama tanpa menambahkan dan/atau mengganti dengan makanan atau minuman lain. Proses menyusui segera setelah melahirkan juga membantu kontraksi uterus sehingga mengurangi kehilangan darah ibu pada masa nifas (Handayani, 2017).

Budaya menyusui pada bayi di Indonesia merupakan sesuatu hal yang penting bagi ibu yang memiliki bayi. Akan tetapi, praktek dalam pemberian ASI eksklusif belum mencapai target yang diharapkan. Di Indonesia, nilai AKB atau angka kematian bayi termasuk tinggi, jika dibandingkan pada beberapa negara ASEAN. Survei Demografi dan Kesehatan Indonesia (SDKI) tahun 2017 menunjukkan Angka Kematian Neonatal (AKN) sebesar 15 per 1.000 kelahiran hidup, Angka Kematian Bayi (AKB) 24 per 1.000 kelahiran hidup, dan Angka Kematian Balita (AKBA) 32 per 1.000 kelahiran hidup. Angka Kematian Balita (AKBA) telah mencapai Target Pembangunan Berkelanjutan (TPB) pada Sustainable Development Goals (SDG's) 2030 yaitu sebesar 25/1.000 kelahiran hidup dan Indonesia mengharapkan Angka Kematian Neonatal (AKN) dapat mencapai target yaitu 12/1.000 kelahiran hidup (Kementerian Kesehatan RI, 2017).

Program Sustainable Development Goals (SDG's) yang dimulai tahun 2016 hingga 2030 terdiri dari 17 pokok tujuan dengan 169 target dan 240 indikator, sedangkan sektor kesehatan pada SDG's terdapat 4 tujuan, 19 target dan 31 indikator. Target SDG's di bidang kesehatan tertuang pada tujuan (goals) ke 3 salah satunya yaitu mengakhiri kematian bayi dan balita yang dapat dicegah, dengan menurunkan Angka Kematian Neonatal (AKN) hingga 12 per 1.000 Kelahiran Hidup dan Angka Kematian Balita 25 per 1.000 Kelahiran Hidup (Kementerian Kesehatan RI, 2017).

Sehubungan dengan Sustainable Development Goals (SDG's) atau tujuan Pembangunan Berkelanjutan 2030, menyusui merupakan salah satu langkah pertama bagi seorang manusia untuk mendapatkan kehidupan yang sehat dan sejahtera. Sayangnya, tidak semua orang mengetahui hal ini (Kementerian Kesehatan RI, 2017). Faktor yang berperan dalam tingginya $\mathrm{AKB}$ salah satunya adalah rendahnya cakupan ASI Eksklusif, karena tanpa ASI Eksklusif bayi lebih rentan terkena berbagai penyakit yang meningkatkan morbiditas dan mortalitas (Kurniyati et al., 2021). Data Kementerian Kesehatan mencatat, ada kenaikan pada angka pemberian ASI eksklusif, dari 29,5\% pada tahun 2016 menjadi $35,7 \%$ pada 2017 . Angka cakupan tersebut sangat rendah mengingat pentingnya peran ASI bagi kehidupan anak. Target minimal pemberian ASI eksklusif di Indonesia yaitu minimal 50\% sesuai target WHO (Jannah, 2021).

Keberhasilan ASI eksklusif dipengaruhi oleh beberapa faktor salah satunya adalah faktor dukungan dari tenaga kesehatan termasuk bidan. Peran bidan dalam mendukung ASI eksklusif antara lain melalui upaya promosi ASI eksklusif yang dimulai dari masa kehamilan. Dukungan lain yang dapat diberikan bidan yaitu mempersiapkan ibu untuk dapat menyusui dengan baik dengan melakukan perawatan payudara selama kehamilan (Septikasari, 2018).

Berdasarkan latar belakang ini peneliti terdorong untuk mengetahui adakah hubungan sikap dan dukungan tenaga kesehatan dengan keberhasilan pemberian ASI eksklusif di Wilayah Puskesmas Berangas Kabupaten. Barito Kuala.

\section{METODE PENELITIAN}

Jenis penelitian ini adalah penelitian kuantitatif dengan menggunakan rancangan penelitian studi korelasi dan desain cross sectional (potong lintang). Tujuan penelitian ini adalah untuk mengetahui hubungan dukungan tenaga kesehatan dengan keberhasilan pemberian ASI eksklusif di wilayah Berangas Kabupaten Barito Kuala. Populasi dalam penelitian ini adalah seluruh ibu yang memiliki bayi umur 6-12 bulan di wilayah kerja Puskesmas Berangas Kab. Barito Kuala. Teknik pengambilan sampel dilakukan dengan teknik accidental sampling, sehingga sampel dalam penelitian ini berjumlah 78 responden. Penelitian dilakukan di Puskesmas Berangas Kab. Barito Kuala. Teknik pengumpulan data pada penelitian ini dilakukan dengan melakukan observasi kemudian dianalisis. Observasi dilakukan dengan bantuan lembar observasi untuk menilai sikap, dukungan tenaga kesehatan dan keberhasilan pemberian ASI Ekslusif. Analisis data yang dilakukan untuk membuktikan dari hipotesis penelitian. Hubungan antar variabel ditentukan dengan menggunakan uji analisis statistik bivariat yaitu $C h i$ Square dengan program Statistical Package for Social Science (SPSS) for windows versi 23.0.

\section{HASIL}

Penelitian ini dilakukan terhadap 78 responden yang merupakan Ibu yang memiliki bayi berusia 6-12 bulan. Hasil penelitian dapat dilihat pada

\section{Analisis Univariat}

Tabel 1. Distribusi Responden berdasarkan Sikap dalam memberikan ASI eksklusif

\begin{tabular}{ccc}
\hline Sikap & f & \% \\
\hline Positif & 53 & 67,95 \\
Negatif & 25 & 32,05 \\
\hline Total & 78 & 100,0 \\
\hline & (Sumber : Data primer, 2021)
\end{tabular}

Tabel 1 diatas menunjukan bahwa dari 78 responden yang diteliti, 53 orang $(67,95 \%)$ diantaranya memiliki sikap positif terhadap pemberian ASI eksklusif, dan 25 orang $(32,05 \%)$ lainnya memiliki sikap negatif terhadap pemberian ASI eksklusif. 
Tabel 2. Distribusi Responden berdasarkan Dukungan Tenaga Kesehatan dalam memberikan ASI eksklusif

\begin{tabular}{ccc}
\hline Dukungan & f & \% \\
\hline Baik & 61 & 78,20 \\
Kurang & 17 & 21,80 \\
\hline Total & 78 & 100,0 \\
\hline & (Sumber : Data primer, 2021)
\end{tabular}

Tabel diatas menunjukan bahwa dari 78 responden yang diteliti, 61 orang $(78,2 \%)$ diantaranya mendapat dukungan yang baik dari tenaga kesehatan dan 17 orang $(21,80 \%)$ kurang mendapatkan dukungan dari tenaga kesehatan.

Tabel 3. Distribusi Responden berdasarkan Keberhasilan ASI eksklusif

\begin{tabular}{|c|c|c|}
\hline $\begin{array}{c}\text { Keberhasilan ASI } \\
\text { eksklusif }\end{array}$ & $\mathbf{f}$ & $\%$ \\
\hline Berhasil & 49 & 62,82 \\
\hline Tidak Berhasil & 29 & 37,18 \\
\hline Total & 78 & 100,0 \\
\hline
\end{tabular}

Tabel 3 di atas menunjukan bahwa dari 78 responden yang diteliti, masih ada 29 orng (37,18)\% tidak berhasil memberikan ASI eksklusif dan 49 orang (62,82\%) berhasil memberikan ASI eksklusif.

\section{Analisa Bivariat}

Tabel 4. Hubungan Sikap dengan Keberhasilan ASI Eksklusif di Wilayah Kerja Puskesmas Berangas Kab. Barito Kuala

\begin{tabular}{lcccccc}
\hline \multirow{3}{*}{ Sikap } & \multicolumn{3}{c}{ Keberhasilan ASI eksklusif } & \multicolumn{2}{c}{ Total } \\
\cline { 2 - 6 } & \multicolumn{2}{c}{ Berhasil } & \multicolumn{2}{c}{ Tidak Berhasil } & & \\
\cline { 2 - 6 } & f & \% & f & \% & f & \% \\
\hline Positif & 39 & 50 & 14 & 17,95 & 53 & 67,95 \\
\hline Negatif & 7 & 8,97 & 18 & 23,08 & 25 & 32,05 \\
\hline Jumlah & 46 & 58,97 & 32 & 27,14 & 78 & 100.0 \\
\hline
\end{tabular}

p value $=0,004$

Tabel 4 di atas menunjukkan bahwa dari 78 responden yang diteliti, responden dengan sikap positif berhasil memberikan ASI eksklusif sebanyak 39 orang (50\%), dan 14 orang lainnya $(17,95 \%)$ tidak berhasil memberikan ASI eksklusif. Sedangkan, responden dengan sikap negatif terdapat 7 orang $(8,97 \%)$ berhasil memberikan ASI eksklusif dan 18 orang lainnya $(23,08 \%)$ tidak berhasil memberikan ASI eksklusif. Hasil penelitian secara statistik menunjukkan $p=0,004$ atau $<0,05$. Artinya ada hubungan sikap dengan keberhasilan ASI Eksklusif di wilayah kerja Puskesmas Berangas Kab. Barito Kuala.
Tabel 5. Hubungan Dukungan Tenaga Kesehatan dengan Keberhasilan ASI Eksklusif di Wilayah Kerja Puskesmas Berangas Kab. Barito Kuala

\begin{tabular}{lcccccc}
\hline \multirow{2}{*}{$\begin{array}{c}\text { Dukungan } \\
\text { Petugas }\end{array}$} & \multicolumn{2}{c}{ Keberhasilan ASI eksklusif } & \multicolumn{2}{c}{ Total } \\
\cline { 2 - 7 } Kesehatan & \multicolumn{2}{c}{ Berhasil } & \multicolumn{2}{c}{ Tdk Berhsil } & & \\
\cline { 2 - 7 } & $\mathbf{f}$ & $\mathbf{\%}$ & $\mathbf{f}$ & $\mathbf{\%}$ & $\mathbf{f}$ & \% \\
\hline Baik & 47 & 60,26 & 14 & 17,95 & 61 & 78,21 \\
\hline Kurang & 2 & 2,56 & 15 & 19,23 & 17 & 21,79 \\
\hline Jumlah & 49 & 62,82 & 29 & 37,18 & 78 & 100.0 \\
\hline
\end{tabular}

p value $=0,007$

Tabel 5 menunjukkan bahwa dari 78 responden yang diteliti, responden yang mendapatkan dukungan dari tenaga kesehatan dengan baik berhasil memberikan ASI eksklusif sebanyak 47 orang $(60,26 \%)$, dan 14 orang lainnya $(17,95 \%)$ tidak berhasil memberikan ASI eksklusif. Sedangkan, responden yang kurang mendapatkan dukungan dari tenaga kesehatan hanya 2 orang $(2,56 \%)$ berhasil memberikan ASI eksklusif dan 15 orang lainnya $(19,23 \%)$ tidak berhasil memberikan ASI eksklusif. Hasil penelitian secara statistik menunjukkan $p=0,007$ atau $<0,05$. Artinya ada hubungan dukungan tenaga kesehatan dengan keberhasilan ASI Eksklusif di wilayah kerja Puskesmas Berangas Kab. Barito Kuala.

\section{PEMBAHASAN}

\section{Analisis univariat}

Penelitian menunjukan bahwa dari 78 responden yang diteliti, 53 orang $(67,95 \%)$ diantaranya memiliki sikap positif terhadap pemberian ASI eksklusif. Sikap dipengaruhi oleh berbagai macam faktor diantaranya pengalaman pribadi, pengaruh orang lain yang dianggap penting, pengaruh kebudayaan, media masa, lembaga pendidikan dan lembaga agama, pengaruh faktor emosional. Sikap seseorang dapat berubah dengan diperolehnya tambahan informasi tentang objek tertentu. Sikap muncul dari berbagai penilaian yaitu kondisi, dan kecenderungan perilaku. Sikap juga dapat berubah dari pengalaman dan faktor bawaan maupun bujukan misalnya dengan penyuluhan atau pendidikan kesehatan (Soekidjo Notoatmodjo, 2010).

Peneltiian juga menunjukan bahwa dari 78 responden yang diteliti, masih ada 17 orang $(21,80 \%)$ kurang mendapatkan dukungan dari tenaga kesehatan. Peran tenaga kesehatan khususnya bidan dalam mendukung ASI eksklusif antara lain melalui upaya promosi ASI eksklusif yang dimulai dari masa kehamilan. Dukungan lain yang dapat diberikan bidan yaitu mempersiapkan ibu untuk dapat menyusui dengan baik dengan melakukan perawatan payudara selama kehamilan untuk menjaga kebersihan payudara, kesiapan puting dan memastikan ASI sudah keluar sebelum kelahiran bayi. Bidan juga dapat memfasilitasi ibu untuk melakukan inisiasi menyusu dini (IMD) pada satu jam pertama setelah bayi lahir, 
tidak memberikan susu formula dan melakukan rawat gabung (Septikasari, 2018).

Penelitian ini menunjukan bahwa dari 78 responden yang diteliti, masih ada 29 orng $(37,18 \%)$ tidak berhasil memberikan ASI eksklusif dan 49 orang $(62,82 \%)$ berhasil memberikan ASI eksklusif. Proverawati Atikah (2010) menyatakan bahwa ibu menyusui membutuhkan dukungan dan pertolongan, baik ketika akan memulai menyusui maupun melanjutkan menyusui. Sebagai langkah awal, para ibu menyusui membutuhkan bantuan sejak kehamilan dan setelah melahirkan yang meliputi pemberian dukungan dalam pemberian ASI hingga 2 tahun, perawatan kesehatan maupun dukungan dari keluarga dan lingkungannya.

Kegagalan dalam memberikan ASI eksklusif sebagai akibat dari rasa khawatir Ibu bahwa ASI tidak mencukupi kebutuhan bayinya justru berpotensi meningkatkan pemberian susu formula atau makanan tambahan secara dini yang dapat menyebabkan bayi tidak menyusu secara adekuat. Kondisi tersebut berdampak pada penurunan produksi ASI. Hal ini sejalan dengan pendapat (Klikdokter, 2016) yang menyatakan bahwa jumlah produksi ASI tergantung dari berapa banyak bayi menyusu. Semakin sering bayi menyusu, semakin banyak hormon prolaktin dilepaskan, dan semakin banyak produksi ASI. Sebaliknya, produksi ASI akan berkurang secara bertahap jika frekuensi menyusui juga berkurang.

Kondisi tersebut menggambarkan perlunya pemberdayaan pada ibu dan keluarga sejak sebelum bersalin mengenai manajemen menyusui. Informasi ini dapat disampaikan saat kunjungan ANC yang dilakukan ibu pada masa kehamilan.

Ibu yang memiliki riwayat keberhasilan memberikan ASI eksklusif memiliki peluang yang lebih besar untuk kembali berhasil memberikan ASI eksklusif pada anak berikutnya. Pengalaman keberhasilan tersebut merupakan sumber kepercayaan diri yang berasal dari pengalaman nyata. Sebaliknya kegagalan ibu memberikan ASI eksklusif sebelumnya akan menurunkan peluang keberhasilan pemberian ASI eksklusif. Sehingga diperlukan dukungan dan motivasi dari berbagai pihak untuk semua Ibu terutama Ibu baru, karena akan berdampak terhadap kesuksesan pemberian ASI eksklusif pada anak yang berikutnya.

\section{Analisa Bivariat}

Penelitian ini menunjukkan bahwa dari 78 responden yang diteliti, Responden dengan sikap positif berhasil memberikan ASI eksklusif sebanyak 39 orang (50\%), dan 14 orang lainnya (17,95\%) tidak berhasil memberikan ASI eksklusif. sedangkan responden dengan sikap negatif terdapat 7 orang $(8,97 \%)$ berhasil memberikan ASI eksklusif dan 18 orang lainnta $(23,08 \%)$ tidak berhasil memberikan ASI eksklusif. Hasil penelitian secara statistik menunjukkan $p=0,004$ atau $<0,05$. Artinya ada hubungan sikap dengan keberhasilan ASI Eksklusif di wilayah kerja Puskesmas Berangas Kab. Barito Kuala.
Sikap adalah suatu bentuk eveluasi atau reaksi perasaan, sikap dipandang sebagai perasaan baik memihak atau melawan suatu objek pisikologis. Sikap seseorang terhadap suatu objek adalah perasaan mendukung atau memihak maupun perasaan tidak mendukung atau tidak memihak pada objek tertentu (Azwar, 2013).

Sikap dipengaruhi oleh berbagai macam faktor diantaranya pengalaman pribadi, pengaruh orang lain yang dianggap penting, pengaruh kebudayaan, media masa, lembaga pendidikan dan lembaga agama, pengaruh faktor emosional. Sikap seseorang dapat berubah dengan diperolehnya tambahan informasi tentang objek tertentu. Sikap muncul dari berbagai penilaian yaitu kondisi, dan kecenderungan perilaku. Sikap juga dapat berubah dari pengalaman dan faktor bawaan maupun bujukan misalnya dengan penyuluhan atau pendidikan kesehatan (Notoatmodjo,2010). Pendidikan kesehatan yang dilakukan secara teratur akan mengubah sikap responden menjadi lebih baik dan bermanfaat bagi responden. Sehingga akan meningkatkan angka pemberian ASI eksklusif.

Penelitian ini menunjukkan bahwa dari 78 responden yang diteliti, responden yang mendapatkan dukungan dari tenaga kesehatan dengan baik berhasil memberikan ASI eksklusif sebanyak 47 orang $(60,26 \%)$, dan 14 orang lainnya $(17,95 \%)$ tidak berhasil memberikan ASI eksklusif. Sedangkan, responden yang kurang mendapatkan dukungan dari tenaga kesehatan hanya 2 orang $(2,56 \%)$ berhasil memberikan ASI eksklusif dan 15 orang lainnya $(19,23 \%)$ tidak berhasil memberikan ASI eksklusif.

Hasil penelitian secara statistik menunjukkan $p=0,007$ atau $<0,05$. Artinya ada hubungan dukungan tenaga kesehatan dengan keberhasilan ASI Eksklusif di wilayah kerja Puskesmas Berangas Kab. Barito Kuala.

Dalam teori PRECEDE-PROCEED, dukungan tenaga kesehatan termasuk dalam faktor-faktor penguat (reinforcing factors) yang mendorong dan memperkuat terjadinya perilaku (Rahmiyati Ria, Widyasih Hesty, 2019). Bidan diakui sebagai tenaga professional yang bertanggung jawab dan akuntabel, yang bekerja sebagai mitra perempuan untuk memberikan dukungan, asuhan mulai dari masa kehamilan, persalinan, nifas dan bayi baru lahir (Argaheni et al., 2021).

Undang-Undang Nomor 4 Tahun 2019 tentang kebidanan, dalam pasal 47 mengatakan bahwa bidan dapat berperan sebagai pemberi pelayanan kebidanan, pengelola pelayanan kebidanan, penyuluh dan konselor, pendidik, pembimbing, dan fasilitator klinik, penggerak peran serta masyarakat dan pemberdayaan perempuan dan atau peneliti penyelenggaraan praktik kebidanan.

Dalam memberikan asuhannya, bidan senantiasa melibatkan ibu dan keluarganya sebagai satu kesatuan, agar terbentuk lingkungan keluarga yang sehat dan berdaya, menunjang pada kehidupan selanjutnya. Dukungan dari para profesional di bidang kesehatan sangat diperlukan bagi ibu, terutama primipara. Pendidikan tentang pentingnya menyusui harus 
diberikan sejak masa antenatal, yang dilakukan oleh semua tenaga kesehatan baik bidan maupun dokter. Tenaga kesehatan memberikan informasi dan penyuluhan mengenai ASI dan menyusui pada ibu bayi maupun suami.

Kontribusi unik dari seorang bidan dibidang kesehatan masyarakat adalah bahwasanya bidan bekerja dengan perempuan, suami dan keluarganya selama melewati masa kehamilan, persalinan dan masa nifas untuk memberikan asuhan yang aman dan holistic.

\section{KESIMPULAN}

Hasil penelitian menunjukkan bahwa 53 orang $(67,95 \%)$ memiliki sikap positif terhadap pemberian ASI eksklusif, 61 orang $(78,2 \%)$ diantaranya mendapat dukungan yang baik dari tenaga kesehatan, 40 orang $(62,82 \%)$ berhasil memberikan ASI eksklusif. Terdapat hubungan yang bermakna antara sikap Ibu dengan keberhasilan pemberian ASI eksklusif dengan nilai p sebesar 0,004 artinya semakin positif sikap ibu maka tingkat keberhasilan dalam pemberian ASI eksklusif juga akan meningkat. Terdapat hubungan yang bermakna antara dukungan tenaga kesehatan dengan keberhasilan pemberian ASI eksklusif dengan nilai p sebesar 0,007 artinya semakin baik dukungan yang diberikan oleh tenaga kesehatan maka keberhasilan pemberian ASI eksklusif juga kan meningkat.

Diharapkan tenaga kesehatan khususnya Bidan dapat memberikan asuhan kebidanan secara komprehensif kepada pasien mulai dari kehamilan, persalinan, nifas BBL dan keluarga berencana sehingga keberhasilan pemberian ASI eksklusif dapat meningkat.

\section{AKNOWLEDGEMENT}

Ucapan terima kasih penulis sampaikan kepada semua pihak yang sudah berkontribusi menyukseskan penelitian ini sampai akhir, terutama pejabat PUSKESMAS Berangas Kab. Barito Kuala, dan Akademi Kebidanan Bunga Kalimantan.

\section{DAFTAR PUSTAKA}

Argaheni, N. B., Putri, N. R., Yani, D. P., Prihartini, S. D., Muzayyaroh, M., Agussafutri, W. D., Azizah, N., Anggraini, D. D., Saragih, H. S., \& Haslan, H. (2021). Konsep Dasar Kebidanan. Yayasan Kita Menulis.

Azwar, S. (2013). Sikap Manusia dan Pengukurannya. Pusat Belajar Offset.

Handayani, N. S. (2017). TINGKAT PENGETAHUAN IBU MENYUSUI TENTANG PEMBERIAN ASI EKSKLUSIF DI DESA MADUREJO PRAMBANAN SLEMAN DAERAH ISTIMEWA YOGYAKARTA.

Jannah, I. (2021). PENATALAKSANAAN PRODUKSI ASI TIDAK LANCARPADA IBU NIFAS POST SC DI BPM SITI HOTIJAH S. ST,. M. M Kes. Bd. Stikes Ngudia Husada Madura.
Kementerian Kesehatan RI. (2017). Profil Kesehatan Indonesia 2017 (Vol. 1227, Issue July). https://doi.org/10.1002/qj

Klikdokter. (2016). Jumlah ASI dan Cara Meningkatkannya. https://www.klikdokter.com/tanyadokter/read/2808627/jumlah-asi-dan-carameningkatkannya

Kurniyati, E. M., Sarti, S., \& Irawati, B. (2021). Pengaruh Inisiasi Menyusui Dini Terhadap Perubahan Suhu Tubuh Bayi Baru Lahir. Journal Of Health Science (Jurnal Ilmu Kesehatan), 6(1), 32-35.

Proverawati Atikah, R. E. (2010). Kapita selekta ASI dan menyusui (Cetakan I,). Nuha Medika.

Rahmiyati Ria, Widyasih Hesty, Y. S. M. (2019). PENGARUH E-BOOKLET TENTANG ASI EKSKLUSIF TERHADAP PENINGKATAN PENGETAHUAN IBU HAMIL TRIMESTER III [Poltekkes Kemenkes Yogyakarta]. http://eprints.poltekkesjogja.ac.id/id/eprint/2194

Septikasari, M. (2018). Peran Bidan dalam ASI Eksklusif di Kabupaten Cilacap. Jurnal Aisyah: Jurnal Ilmu Kesehatan, 3(2), 109-114.

Soekidjo Notoatmodjo. (2010). Ilmu Perilaku Kesehatan (Edition Ce). Penerbit Rineka Cipta: JAKARTA., 2010. 